\title{
Smart approach for cost-effective genotyping of single nucleotide polymorphisms
}

\author{
Muhammad U. Ghani, Muhammad F. Sabar*, Muhammad Akram, \\ Centre for Applied Molecular Biology, University of the Punjab, 87-West Canal Bank Road \\ Thokar Niaz Baig Lahore, Pakistan. 53700. \\ *Corresponding author: farooq.camb@pu.edu.pk
}

\begin{abstract}
Single Nucleotide Polymorphisms (SNPs) are in the prime focus of genomic studies for their probable roles in diagnostics and prognosis of diseases and forensic science. SNaPshot/minisequencing reaction-based genotyping of targeted SNPs is a method of choice due to its fast and reliable detection assay. Here we described smart modifications in minisequencing reaction to make it cost-effective to detect 15 SNPs in a single assay. The target SNPs were amplified in a multiplex PCR from genomic DNA, and these multiplex PCR amplicons were utilized as a template in modified SNaPshot reaction for SNPs identification. The modified protocol was assessed for reproducibility on more than 50 human DNA samples, and it was observed that this modified method is at least five times more productive than the original protocol recommended by the manufacturer. The current smart modifications in SNaPshot reaction were successfully optimized for susceptible asthma SNPs. However, these can be applied for cost-effective genotyping of any type of genomic Single Nucleotide Polymorphisms.
\end{abstract}

Keywords: Assay; genotyping; single nucleotide polymorphism; smart approach; SNaPshot.

\section{Introduction:}

Currently, there is substantial interest in the use of single nucleotide polymorphisms (SNPs) for understanding the genetic basis of complex human diseases. SNPs are the most common type of DNA sequence variations in the human genome (on average once every 200-300 base pairs of the human genome) that are responsible for functional changes (Tebbutt et al., 2007, Shahid et al., 2015). The use of SNapShot minisequencing has quite increased due to its fast and reliable detections of multiple SNPs in a single polymerase chain reaction (PCR). This method is a preferred choice for SNPs based diagnostics and forensic studies because of its robustness, multiplexing, detection sensitivity, and less dependence on quality and quantity of DNA (Gilbert et al., 2007, Babol-Pokora \& Berent, 2008, Sabar et al., 2016).

Many disease association and genetic screening studies using SNaPshot minisequencing assay revealed that it is a very reliable method for the detection of SNPs. The assay was very successful in determining the significant association of GATA3 haplotypes with asthma in Finnish families (Pykalainen et al., 2005). Single nucleotide polymorphism of $B C L 11 A$ and $H B S 1 L-M Y B$ genes is found to be strongly associated with $\mathrm{HbF}$ (fetal 
hemoglobin) level using the same approach (Fanis et al., 2014). It is also an important tool for screening disease-related mutation for the purpose of the diagnostic (Sagong et al., 2013). Bouakaze and co-workers successfully performed the typing of Y-SNP from ancient DNA (5500 to 1800 years old) of southern Siberia origin using SNaPshot minisequencing, showing efficiency, robustness, and convenience of the assay in the field of forensic and evolutionary biology even with too ancient and degraded DNA samples (Bouakaze et al., 2007). Fas gene is a member of the TNF-receptor superfamily, encodes a protein that mediates apoptosis (programmed cell death). SNaPshot assay was employed to confirm the outcomes of a direct sequencing-based study that developed the novel DNA biomarkers present in the Fas gene associated with some economical traits in cattle (Kim et al., 2016).

This shows that SNaPshot minisequencing is a powerful tool that can serve the scientific community in forensic (Huang et al., 2010), medical genetics (Fanis et al., 2014), and diagnostics fields (Sagong et al., 2013). In most of the studies, the SNaPshot assay was performed according to the manufacturer's provided guidelines, and no doubt, it is a method of choice due to its accuracy, efficacy, reliability, and robustness. Cost-effective research is also one of the priorities of the scientific community, especially from developing or less developed countries.

This study presents a cost-effective 15plex minisequencing protocol that was optimized to decrease the cost of qualitative detection of 15 "Single Nucleotide Polymorphisms" in a single multiplex PCR.

\section{Materials and methods}

\subsection{Reference samples}

The optimization and validation of costeffective SNaPshot assay were performed on 50 DNA samples (25 normal healthy and 25 asthma patients) of children; The DNA samples were taken from the DNA bank of DNA Core facility-CAMB, University of Punjab. The samples were collected for research purposes after ethical approval from "The Children's Hospital \& The Institute of Child Health" (Ref. No. 01/158/16), and written informed consents were obtained from the guardians/parents of children whose DNA was used in this study.

These DNA samples were extracted from the peripheral blood samples of study participants. DNA Core Facility-CAMB completed ethical approvals and legal formalities for the use of blood samples for research purposes as mentioned in our previous publications (Ghani et al., 2019b, Ghani et al., 2019a, Sabar et al., 2017).

\subsection{SNPs selection and primers designing}

Fifteen genomic SNP variants selected for multiplex PCR are described in Table I. These variants were already reported as potent asthma susceptible genomic variants in different populations; however, their detailed role in asthma development is still to be explored in Pakistani children; therefore, these SNPs were selected to optimize the modified SNP genotyping method which can be used to study the role of these SNPs in the pathogenesis of asthma disease in Pakistan. Twelve pairs of amplification primers were designed with Primer-3 software and technically analyzed for auto dimerization, self-complementarity, etc., by FastPCR software (http://primerdigital.com/tools/pcr.html).

Primers were designed by keeping a minimum difference of 26bp between amplification PCR products. SBE (Single base extension) primers were designed with 
Primer 3 Plus software

(http://bioinfo.ut.ee/primer3-0.4.0/).

Poly-GACT tailing was added on the 5' position of primers to increase the length and keep at least $4 \mathrm{bp}$ difference between single base extension (SBE) primers.

\subsection{Amplification in Multiplex PCR}

Target SNPs were amplified with Phusion U multiplex PCR mix (ThermoFisher
Scientific, Cat\#F562S) in a $15 \mu$ l reaction volume as described in Table II. $05 \mu 1$ of purified PCR amplicons were treated with $1.2 \mu 1$ ExoNuclease-I (01 IU/ $\mu 1)$, and $1.6 \mu 1$ of 5X SAP (Shrimp Alkaline Phosphatase), and the mixture was incubated at $37^{\circ} \mathrm{C}$ for 60 minutes to remove primers and inactivate dNTPs followed by deactivation of these enzymes at $80^{\circ} \mathrm{C}$ for 15 minutes

Table 1. SNPs optimized in 15-plex SNaPshot reaction.

\begin{tabular}{||ccc||}
\hline Sr. No & Gene. & SNP ID \\
\hline 1 & CHI3L1 & rs4950928 \\
2 & CHI3L1 & rs880633 \\
3 & CD14 & rs2569190 \\
4 & IL4 & rs2070874 \\
5 & IL3 & rs40401 \\
6 & IL3 & rs31480 \\
7 & CSF2 & rs25882 \\
8 & IL5 & rs2069812 \\
9 & RAD50 & rs2244012 \\
10 & RAD50 & rs6871536 \\
11 & IL13 & rs1881457 \\
12 & IL13 & rs1800925 \\
13 & IL13 & rs1295686 \\
14 & IL13 & rs20541 \\
15 & IL4 & rs2243250 \\
& & \\
\hline
\end{tabular}


Table 2. Multiplex PCR protocol to amplify SNPs from genomic DNA.

\begin{tabular}{|c|c|c|c|c|c|}
\hline $\begin{array}{l}\text { Amplification } \mathbf{P} \\
\text { Reaction Mix C }\end{array}$ & TR & PCR Amplif & cation Protoce & & \\
\hline PCR & & & & & \\
\hline Component & Volume & Step & Temperature & $\begin{array}{l}\text { Time } \\
5\end{array}$ & Cycles \\
\hline $\mathrm{dH} 2 \mathrm{O}$ & $6 \mu 1$ & Hot Start & $95^{\circ} \mathrm{C}$ & Min. & 1 \\
\hline PCR Ready & & & & 0.45 & \\
\hline Mix & $7.5 \mu 1$ & Denaturation & $95^{\circ} \mathrm{C}$ & Min. & \\
\hline DNA $(25 \mathrm{ng} / \mu \mathrm{l})$ & $01 \mu 1$ & Annealing & $58^{\circ} \mathrm{C}$ & Min. & 30 \\
\hline $\begin{array}{l}\text { Primers Mix } \\
(1 \mu \mathrm{M})\end{array}$ & $0.5 \mu 1$ & Elongation & $72^{\circ} \mathrm{C}$ & $\begin{array}{l}1.30 \\
\min .\end{array}$ & \\
\hline Total & $15 \mu 1$ & $\begin{array}{l}\text { Final } \\
\text { elongation }\end{array}$ & $72^{\circ} \mathrm{C}$ & $\begin{array}{l}10 \\
\min .\end{array}$ & 1 \\
\hline
\end{tabular}

\subsection{Modified SNaPshot Reaction}

Mutiplex SNaPshot reaction was first optimized for genotyping of target SNPs in $10 \mu \mathrm{l}$ reaction as per the protocol of SNaPshot ${ }^{\circledR}$ Multiplex kit (ThermoFisher Scientific, cat\# 4323159) just by varying concentration of SBE primers and amplified multiplex PCR product. The concentration of primers was optimized to the minimum possible concentration by decreasing from $0.2 \mu \mathrm{M}$ to $0.01 \mu \mathrm{M}$ to avoid junk or nonspecific peaks in SNP genotyping results electropherogram. After optimization of standard reaction, modifications were performed in the SNaPshot reaction to make it cost-effective. For $5 \mu \mathrm{l}$ reaction volume, $5 \mathrm{X}$ sequencing buffer (BigDye ver 3.1, ThermoFisher Scientific, cat\# 4337455) was used as a SNaPshot reaction buffer to balance the stoichiometric ratios of PCR reaction components by a stepwise decreasing concentration of "SNaPshot reaction ready mix" from $2.5 \mu 1$ to $0.5 \mu 1$. For 15 SNPs-plex and 05 SNPs-plex, the SNaPshot reaction was optimized by taking
$01 \mu 1$ and $0.5 \mu 1$ of ready mix, respectively (Table III). However, reproducibility of the modified method was only accessed for 15 SNPs-plex.

2.5 Purification of SNaPshot reaction products and Capillary Electrophoresis

$0.5 \mu 1 \quad 5 X \quad$ SAP (Shrimp Alkaline Phosphatase) added in $\mathrm{SNaPshot}$ reaction product and incubated at $37^{\circ} \mathrm{C}$ for one hour with subsequent inactivation of an enzyme at $75^{\circ} \mathrm{C}$ for 15 minutes. $01 \mu \mathrm{l}$ of the enzymatically cleaned product along with $0.05 \mu \mathrm{l}$ of GeneScan-120LIZ (internal size standard-Life Technologies) was added in $8.95 \mu \mathrm{l} \mathrm{HiDi}$ formamide and incubated the mixture at $95^{\circ} \mathrm{C}$ for 05 minutes followed by readily placement of mixture on ice for 03-5 minutes to denature and linearize the $\mathrm{SNaPshot} \mathrm{reaction} \mathrm{product} \mathrm{fragments.} \mathrm{These}$ reaction fragments were placed on $3130 \mathrm{XL}$ Genetic Analyzer for SNP genotyping based on the principle of CE (capillary electrophoresis). GeneMapper IDX analyzed 
the electrophoresis results to interpret the alleles of target SNPs.

\section{Results}

The modified method was successfully optimized to detect 15 SNPs in a single reaction by changing stoichiometric ratios of PCR reaction components as describes in Table III. In optimization-1, the volume of PCR reaction components was reduced to half. Strategy to reduce the volume of reaction components was also optimized for our previous study to analyze the asthma susceptible SNP variants of the ADAM33 gene (Sabar et al., 2016). In optimization-2, we decreased the quantity of SNaPshot ready mix to half of optimization- 1 and added $0.25 \mu \mathrm{l}$ sequencing buffer $(5 \mathrm{X})$ to adjusted stoichiometric ratios of reaction components. In optimization-3, we further decreased the quantity of $\mathrm{SNaPshot}$ ready mix to $1 \mu \mathrm{l}$ and added $0.5 \mu \mathrm{l}$ sequencing buffer $(5 X)$ to adjusted stoichiometric ratios of reaction components.

The optimization-3 is the best-optimized method, and the whole reaction process is demonstrated in Table III. The representative electropherogram of SNPs is given in figure I, and optimized capillary electrophoresis setting/parameters of ABI 3130XL are given in table IV.

Table 3. Optimization of cost-effective SNaPshot genotyping protocol.

\begin{tabular}{|c|c|c|c|c|}
\hline \multirow{2}{*}{$\begin{array}{l}\text { PCR } \\
\text { Components }\end{array}$} & $\begin{array}{l}\text { Standard } \\
\text { Reaction }\end{array}$ & Optimization-1 & Optimization-2 & Optimization-3 \\
\hline & Volume $(\mu \mathrm{l})$ & Volume $(\mu \mathrm{l})$ & Volume $(\mu \mathrm{l})$ & Volume $(\mu \mathrm{l})$ \\
\hline SNaPshot kit & 5 & 2.5 & 1.25 & 1 \\
\hline $\begin{array}{l}\mathrm{dH} 2 \mathrm{O} \\
\mathrm{PCR}\end{array}$ & 2 & 1 & 2 & 2 \\
\hline Amplicons & 2 & 1 & 1 & 1 \\
\hline $\begin{array}{l}\text { SBE Primer } \\
\text { Mix }(0.01 \mu \mathrm{M}) \\
\text { Sequencing }\end{array}$ & 1 & 0.5 & 0.5 & 0.5 \\
\hline $\begin{array}{l}\text { Buffer }(5 X) \\
\text { Total Volume } \\
(\mu \mathrm{l})\end{array}$ & 10 & 0 & 0.25 & 0.5 \\
\hline
\end{tabular}




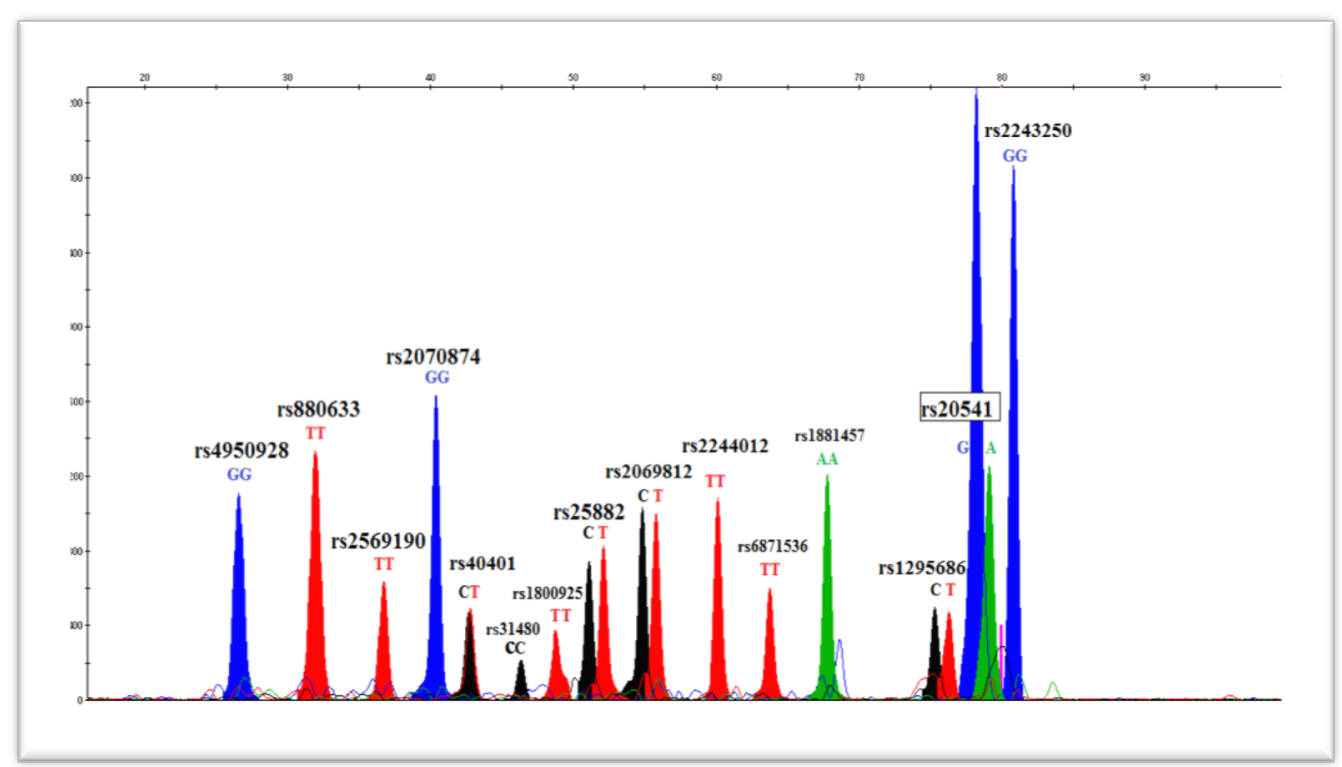

Fig. 1. Different colours of peaks differentiate among alleles. "G" allele is represented by blue, "C" allele by black, " $T$ " by red, and "A" allele by green colour.

Table 4. Parameters of 3130xL Genetic Analyzer to perform electrophoresis of SNaPshot multiplex fragments.

\begin{tabular}{||cc||}
\hline Parameters & $\begin{array}{c}\text { Control Module } \\
\text { (E5 with POP-4 polymer) }\end{array}$ \\
\hline Injection time & $33 \mathrm{Sec}$ \\
Electrophoresis voltage & $15 \mathrm{kV}$ \\
Injection Voltage & $2 \mathrm{KV}$ \\
Capillary Length & $36 \mathrm{~cm}$ \\
Oven temperature & $60{ }^{\circ} \mathrm{C}$ \\
Run Time & $1000 \mathrm{Sec}$ \\
\hline
\end{tabular}


Table 5. The whole optimized \& modified protocol for genomic SNPs analysis.

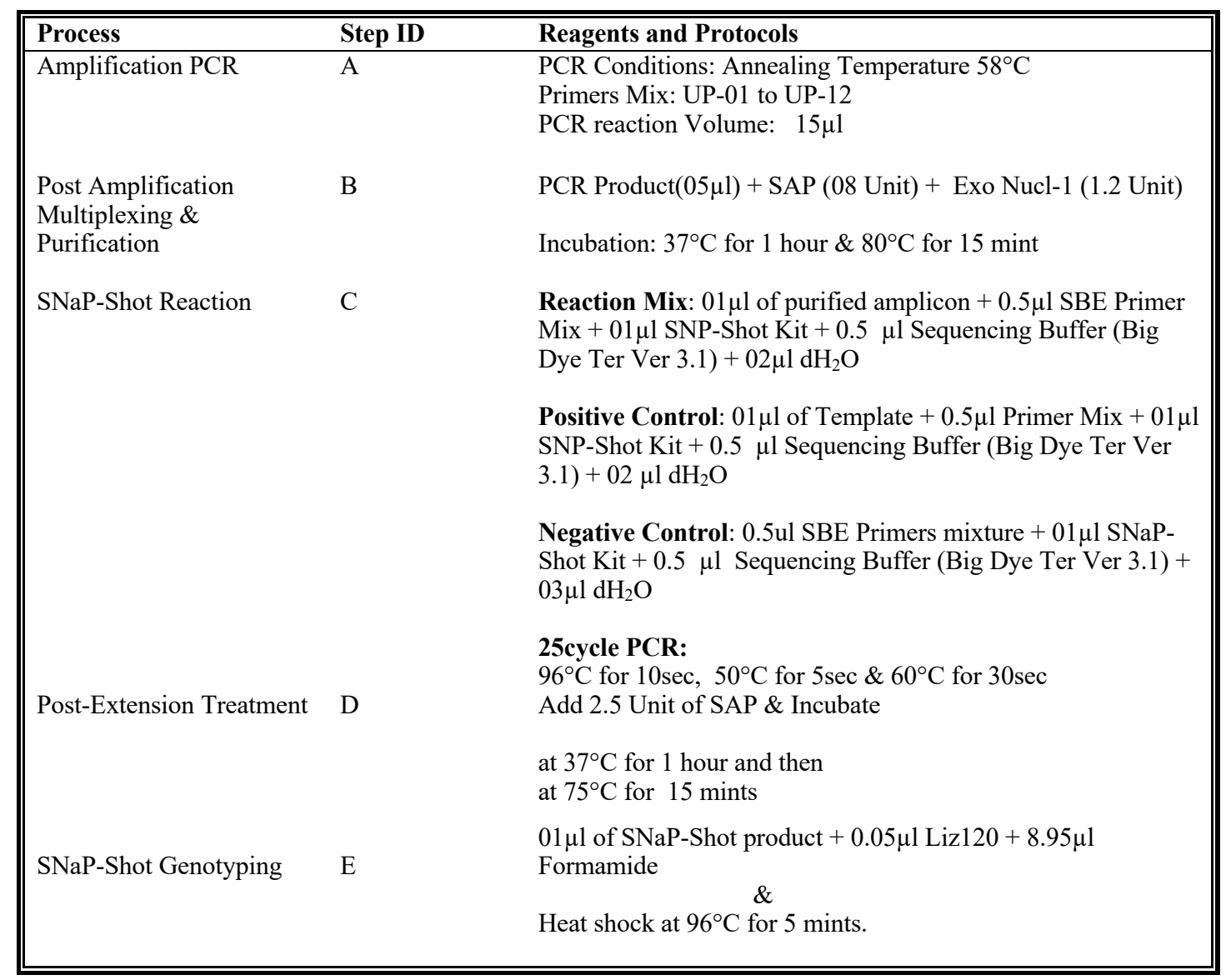

\section{Discussions}

The minisequencing/single base extension assay used in this method utilizes the SNaPshot Multiplex Kit that comprises a ready reaction mixture of four fluorescently labeled dideoxy nucleotide triphosphates (ddNTPs), which allows the incorporation of only one base at the targeted mutation site. The incorporated ddNTPs are identified and distinguished based on the colors produced by fluorescently labeled dyes to call alleles on mutation/polymorphic site(Hurst et al., 2009).

SNaPshot minisequencing assay was first developed by Smith and his co-workers (Smith et al., 1998), and now it has been widely used in medical genetics (Bertoncini et al., 2011), population genetics (Drobnic et al., 2010), disease-related case-control studies (Kumar et al., 2012) and diagnostics (Al-Aama et al., 2019). This technique is equally important in the identification of an individual by determining the haplogroup of mtDNA followed by phylogenetic analysis (Coutinho et al., 2014).

Another important application of SNaPshot assay is the identification of closely related species by comparing the selected portions of the genome to develop biomarkers that lead to the discrimination between species (Maroso et al., 2019, Huang et al., 2011) 
Currently, multiplex SNaPshot assay is successfully used to unravel the genetic basis of many hereditary diseases like ischemic stroke (Yang et al., 2016), asthma (Lyon et al., 2004), and large artery atherosclerotic stroke (Li et al., 2019).

It has an advantage over other genetic techniques that a single multiplex SNaPshot reaction can easily detect multiple SNPs in different genes.

Due to robustness and compatibility with capillary-based genetic analyzers, the manufacturer's standard SNaPshot assay has been adopted in several studies to genotype SNPs located at different positions on the human genome (Sabar et al., 2016, Shahid et al., 2019). So far, none of the studies have been designed to reduce the cost of SNaPshot minisequencing based methodology/research. To the best of our knowledge, the current study is the first effort of its kind that involved some successful modifications in the multiplex SNaPshot technique for cost-effective genotyping of SNPs without affecting the quality of research work. This modified protocol will help the scientific community from developing and very less developed countries where the research budget is very limited.

Originally SNaPshot Multiplex Kit is designed by the manufacturer to analyze 01 to 10 SNPs in a $10 \mu 1$ reaction volume. However, in this article, we present a more cost-effective and productive assay that can analyze up to 15 SNPs in a single tube reaction using $01 \mu \mathrm{l} \mathrm{SNaPshot}$ multiplex kit ready mix instead of $05 \mu l$. With the suggested modifications, a kit of 100 samples with 10X multiplex (1000 SNPs) can be used to analyze about 500 samples with 15X SNPs multiplex (7500 SNPs) that make it cost-effective and more productive relative to standard protocol. It is observed that SBE primers may anneal at nonspecific genomic sites to produce nonspecific single base products; therefore, targeted alleles are needed to observe critically and be confirmed through DNA during the optimization step sequencing technique.

However, SNaPshot genotyping/misequencing protocol is still a method of choice to genotype SNPs due to robustness and cost-effectiveness. The optimized assay was assessed on 25 healthy and 25 asthma patients. The genotyping results were concordant with the results of the assay of the SNaPshot Multiplex Kit without modification.

\section{Conclusion}

The main focus of this study was the modification in SNaPshot minisequencing assay to make it cost-effective without compromising the quality of research data which has been achieved successfully by developing the $15 \mathrm{X}$ multiplex. The SNPs analyzed in the current study have been reported as potential asthma susceptible variants in different populations. We have reported the modified assay's efficiency, providing a low-cost and robust approach to analyze the SNPs efficiently. This approach may also provide sufficient information to understand the role of SNPs in the development of asthma and other diseases in different populations. The reaction success rate with the modified protocol was exactly the same as the reactions performed with the manufacturer's provided standard protocol, suggesting that the quality of analysis work was not compromised over cost. In countries like Pakistan, where the budget for research activities is limited, such smart modifications in assays allow researchers to complete their targets within their limited financial resources without affecting the quality of research work. 


\section{References}

Al-aama, J.; Mahdi, H. B. A.; Salama, M. A.; Bakur, K.; Alhozali, A., Mosli, H., Bahijri, S. M., Bahieldin, A. et al. (2019) Rapid detection of type II diabetes mellitus in Saudi patients via simultaneous screening of multiple SNPs. Biotechnology \& Biotechnological Equipment, 33(1), 13191326.

doi.org/10.1080/13102818.2019.1664321

Babol-pokora, K. \& Berent, J. (2008) SNP-minisequencing as an excellent tool for analysing degraded DNA recovered from archival tissues. Acta Biochim Pol, 55(4), 815-9.

Bertoncini, S.; Blanco-rojo, R.; Baeza, C.; Arroyo-pardo, E.; Vaquero, M. P. et al. (2011) A novel SNaPshot assay to detect genetic mutations related to iron metabolism. Genet Test Mol Biomarkers, 15(3), 173-9. doi: 10.1089/gtmb.2010.0140

Bouakaze, C.; Keyser, C.; Amory, S.; Crubezy, E. \& Ludes, B. (2007) First successful assay of Y-SNP typing by SNaPshot minisequencing on ancient DNA. Int J Legal Med, 121(6), 493-9. doi.org/10.1007/s00414-007-0177-3

Coutinho, A.; Valverde, G.; Fehrenschmitz, L.; Cooper, A.; Barreto R. M. I. et al. (2014) AmericaPlex26: a SNaPshot multiplex system for genotyping the main human mitochondrial founder lineages of the Americas. PLoS One, 9(3), e93292. doi.org/10.1371/journal.pone.0093292

Drobnic, K.; Borsting, C.; Rockenbauer, E.; Tomas, C. \& Morling, N. (2010) Typing of 49 autosomal SNPs by SNaPshot in the Slovenian population. Forensic Sci Int Genet, 4(5), e125-e127. doi.org/10.1016/j.fsigen.2010.01.014

Fanis, P.; Kousiappa, I.; Phylactides, M. \& Kleanthous, M. (2014) Genotyping of BCL11A and HBS1L-MYB SNPs associated with fetal haemoglobin levels: a SNaPshot minisequencing approach. BMC Genomics, 15, 108. doi: 10.1186/1471-2164$15-108$

Ghani, M. U.; Sabar, M. F.; Bano, I.; Shahid, M.; Akram, M. et al. (2019a) Evaluation of ADAM33 gene's single nucleotide polymorphism variants against asthma and the unique pattern of inheritance in Northern and Central Punjab, Pakistan. Saudi Med J, 40(8), 774-780. doi: $10.15537 / \mathrm{smj} .2019 .8 .24411$

Ghani, M. U.; Sabar, M. F.; Bano, I.; Shahid, M.; Akram, M. et al. (2019b) Inheritance Pattern of rs2280089, rs2280090, rs2280091 Snp Variants in Punjabi Population and Association with Asthma Disease. Chest, 155(4), 168A. doi.org/10.1016/j.chest.2019.02.162

Gilbert, M. T.; Sanchez, J. J.; Haselkorn, T.; Jewell, L. D.; Lucas, S. B. et al. (2007) Multiplex PCR with minisequencing as an effective high-throughput SNP typing method for formalin-fixed tissue. Electrophoresis, 28(14), 2361-7. doi: 10.1002/elps.200600589

Huang, C. H.; Chang, M. T.; Huang, M. C. \& LEE, F. L. (2011) Application of the SNaPshot minisequencing assay to species identification in the Lactobacillus casei group. Mol Cell Probes, 25(4), 153-7. doi: 10.1016/j.mcp.2011.03.002

Huang, D.; Gui, C.; Yi, S.; Yang, Q.; Yang, R. et al. (2010) Typing of 24 mtDNA SNPs in a Chinese population using SNaPshot minisequencing. J Huazhong Univ Sci Technolog Med Sci, 30, 291-8. doi:10.1007/s11596-010-0345-4

Hurst, C. D.; Zuiverloon, T. C.; Hafner, C.; Zwarthoff, E. C. \& Knowles, M. A. (2009) A SNaPshot assay for the rapid and 
simple detection of four common hotspot codon mutations in the PIK3CA gene. BMC Res Notes, 2, 66. doi: 10.1186/1756-0500-266

Kim, S. C.; Lee, S. H.; Lee, J. W.; Kim, T. H. \& Choi, B. H. (2016) Identification of Single Nucleotide Polymorphism Marker and Association Analysis of Marbling Score in Fas Gene of Hanwoo. Asian-Australas J Anim Sci, 29(1), 23-8. doi: 10.5713/ajas. 14.0812.

Kumar, A.; Sharma, S.; Agrawal, A. \& Ghosh, B. (2012) Association of the 1072G/A polymorphism in the LTC4S gene with asthma in an Indian population. Int Arch Allergy Immunol, 159, 271-7. doi: $10.1159 / 000336675$

Li, J. L.; Liu, L. Y.; Jiang, D. D.; Jiang, Y. Y.; Zhou, G. Q. et al. (2019) Associations between GUCY1A3 genetic polymorphisms and large artery atherosclerotic stroke risk in Chinese Han population: a case-control study. Lipids in Health and Disease, 18(1), 233. doi: 10.1186/s12944-019-1177-2.

Lyon, H.; Lange, C.; Lake, S.; Silverman, E. K.; Randolph, A. G. et al. (2004) IL10 gene polymorphisms are associated with asthma phenotypes in children. Genet Epidemiol, 26(2), 155-65. doi.org/10.1002/gepi.10298.

Maroso, F.; Pérez D. G. C.; Iglesias, D.; Cao, A.; Díaz, S. et al. (2019) A Useful SNP Panel to Distinguish Two Cockle Species, Cerastoderma edule and C. glaucum, Co-Occurring in Some European Beds, and Their Putative Hybrids. Genes, 10(10), 760. doi: 10.3390/genes 10100760

Pykalainen, M.; Kinos, R.; Valkonen, S.; Rydman, P.; Kilpelainen, M. et al. (2005) Association analysis of common variants of STAT6, GATA3, and STAT4 to asthma and high serum IgE phenotypes. J Allergy Clin
Immunol, $\quad$ 115(1), 80-7. doi:10.1016/j.jaci.2004.10.006.

Sabar, M. F.; Ghani, M. U.; Shahid, M.; Sumrin, A.; Ali, A. et al. (2016) Genetic variants of ADAM33 are associated with asthma susceptibility in the Punjabi population of Pakistan. J Asthma, 53(4), 341-8. doi.org/ $10.3109 / 02770903.2015 .1124441$

Sabar, M. F.; Shahid, M.; Bano, I.; Ghani, M. U.; Akram, M. et al. (2017) rs 12603332 is associated with male asthma patients specifically in urban areas of Lahore, Pakistan. J Asthma, 54(9), 887-892. doi: 10.1080/02770903.2016.1277539

Sagong, B.; Baek, J. I.; Oh, S. K.; Na, K. J.; Bae, J. W. et al. (2013) A rapid method for simultaneous screening of multi-gene mutations associated with hearing loss in the Korean population. PLoS One, 8(3), e57237. doi: 10.1371/journal.pone.0057237.

Shahid, M.; Sabar, M. F.; Bano, I.; Rahman, Z.; Iqbal, Z. et al. (2015) Sequence variants on $17 \mathrm{q} 21$ are associated with the susceptibility of asthma in the population of Lahore, Pakistan. J Asthma, 52(2), 777-84. doi: 10.3109/02770903.2015.1012590.

Shahid, M.; Tayyab, U.; Kousar, S.; Ghani, M. U.; Sabar, M. F. et al. (2019) rs153109 as Possible Indicator of Effectiveness of Vitamin D Supplements for Suppressing Copd Symptoms. Chest, 155(4), 219A.

doi.org/10.1016/j.chest.2019.02.211

Smith, W. M.; Van O. N. J.; Fox, E. A.; Kolodner, R. D.; Vijg, J. et al. (1998) Accurate, high-throughput "snapshot" detection of hMLH1 mutations by twodimensional DNA electrophoresis. Genet Test, 2(1), 43-53. doi: 10.1089/gte.1998.2.43 
Tebbutt, S. J.; James, A. \& Paré, P. D. (2007) Single-Nucleotide Polymorphisms and Lung Disease*. Chest, 131(4), 12161223. doi: $10.1378 /$ chest. $06-2252$

Yang, D.; Huang, X.; Cui, C.; Zhang, Y.; Li, Y. et al. (2016) Genetic Variants in the Transcriptional Regulatory Region of the ALOX5AP gene and Susceptibility to Ischemic Stroke in Chinese Populations. Sci Rep, 6, 1-8. doi: 10.1038/srep29513
Submitted $\quad: 05 / 01 / 2020$

Revised :03/04/2020

Accepted $\quad: 14 / 05 / 2020$

DOI $\quad: 10.48129 /$ kjs.v48i2.8957 